\title{
Arthroscopic treatment of tibial eminence fractures using double-loop endobutton device: Surgical technique and short-term treatment outcomes
}

\author{
Ahmet Yıldırım, MD®D, Bahattin Kerem Aydın, MD®i), Sadettin Çiftci, MD®, Ali Güleç, MD (1) \\ Department of Orthopedics and Traumatology, Selçuk University Faculty of Medicine, Konya, Turkey
}

Tibial eminence avulsion fracture is a significant intraarticular injury in children and adults. It is used as a synonym of tear of anterior cruciate ligament (ACL) in adults. ${ }^{[1,2]}$ The classification of these fractures was defined by Meyer's and McKeever ${ }^{[1]}$ as type I: nondisplaced or minimal displaced fractures, type II: elevated fractures with intact posterior part of eminence, type IIIa: completely displaced eminence fractures without rotation, and type IIIb: displaced eminence fractures with rotation. Zaricznyj ${ }^{[3,4]}$ modified that classification such that a comminute fracture should be classified as type IV.

Tibial eminence fractures should be considered as chondroepiphyseal avulsions of the ACL insertion and might cause knee instability; therefore, excellent treatment would be needed to exclude late osteoarthritis and instability. ${ }^{[4]}$ Generally, conservative treatment options are preferred for

Received: April 20, 2020

Accepted: May 23, 2020

Published online: September 11, 2020

Correspondence: Ahmet Yıldırım, MD. Selçuk Üniversitesi Tıp Fakültesi Ortopedi ve Travmatoloji Anabilim Dalı, 42250 Selçuklu, Konya, Türkiye.

E-mail: drorto@yandex.com

Doi: $10.5606 /$ ehc. 2020.75636

Citation: Yıldırım A, Aydın BK, Çiftci S, Güleç A. Arthroscopic treatment of tibial eminence fractures using double-loop endobutton device: Surgical technique and short-term treatment outcomes. Jt Dis Relat Surg 2020;31(3):456-462.

(2020 All right reserved by the Turkish Joint Diseases Foundation

This is an open access article under the terms of the Creative Commons Attribution-NonCommercial License, which permits use, distribution and reproduction in any medium, provided the original work is properly cited and is not used for commercial purposes (http://creativecommons.org/licenses/by-nc/4.0/).

\section{ABSTRACT}

Objectives: This study aims to explain the arthroscopic surgical technique of double-loop endobutton device for tibial eminence fractures and share the outcomes of this treatment method.

Patients and methods: Thirteen patients (10 males, 3 females; mean age $19.9 \pm 5.6$ years; range, 14 to 34 years) with tibial eminence fractures type II, IIIa, and IIIb were analyzed retrospectively between March 2017 and March 2019. Knee laxity, Tegner Lysholm knee scores, the International Knee Documentation Committee (IKDC) scores, knee mobility, Lachman test, and bone union were analyzed after the arthroscopic fracture fixation with double-loop endobutton device at first and sixth months after surgery.

Results: First month mean IKDC scores were 38.0 7.0 and mean Tegner Lysholm scores were 50.3 \pm 5.8 . Sixth month mean IKDC scores were $80.2 \pm 4.0$ and mean Tegner Lysholm scores were 87.1 \pm 5.4 . All patients showed negative Lachman test and negative pivot-shift test at final follow-up. Radiological bone union without reduction loss was also seen in all patients.

Conclusion: Using double-loop endobutton device provides successful results to fix tibial eminence fractures.

Keywords: Anterior cruciate ligament, arthroscopic fixation, arthroscopy, endobutton device, tibial eminence fracture.

type I fractures and surgical methods stand out for other types of eminence fractures. Using arthroscopy for the surgical treatment of eminence fractures provides low soft tissue damage, less postoperative pain, hospital stay, and complications. ${ }^{[5]}$

Many surgical methods and implants for fixation have been suggested for arthroscopic treatment of tibial eminence avulsion fractures such as cannulated screws, anchors, Kirschner wires, and sutures..$^{[1,5-7]}$ Suture fixation with fiber wire is known as the most popular method in arthroscopic techniques while it has some handicaps about stability, early rehabilitation, and knee function restoring. ${ }^{[5,8]}$ A biomechanically more stable device for the arthroscopic fixation of tibial eminence 
would provide early rehabilitation and knee function restoring. It was seen that double-loop endobutton devices had biomechanical superiority over other implants for acromioclavicular dislocations or ankle syndesmosis injuries. ${ }^{[9-11]}$ The usage of this implant for the tibial eminence fractures in the literature has been rare and limited patient outcomes were shared. ${ }^{[3]}$ For this reason, in this study, we aimed to explain the arthroscopic surgical technique of double-loop endobutton device for tibial eminence fractures and share the outcomes of this treatment method. ${ }^{[12]}$

\section{PATIENTS AND METHODS}

The retrospective study was conducted at Selçuk University Faculty of Medicine Medical Faculty between March 2017 and March 2019. Thirteen patients (10 males, 3 females; mean age $19.9 \pm 5.6$ years; range, 14 to 34 years) with tibial eminence fractures type II and III according to Meyer's and McKeever's criteria $^{[1]}$ were analyzed retrospectively. After the physical examination of these patients, radiography (X-ray) and computed tomography (CT) of the knee joint were taken for all patients for verification of the diagnosis and classification. Magnetic resonance imaging was performed on a few patients to exclude concomitant injuries (Figure 1). When this study had started, $70.0 \%$ of patients $(n=9)$ had their injuries present for less than one week, and only $15 \%$ of them $(n=2)$ had injuries for over than three weeks. One of the neglected cases had been treated with long leg cast at another trauma center and came at the fourth week of trauma and the other neglected case had had an alternative treatment by a bonesetter and was seen at the outpatient clinic at the sixth week after initial trauma. Thus eight patients were classified to have type IIIa and IIIb fracture and the others were classified to have type II fracture. Types of injury were road traffic accident (motorcycle/ non-vehicle) in six patients and sports injury, skiing, and fall in seven patients (Table I). The exclusion criteria were as follows: concomitant fractures as tibial plateau fracture, neurovascular injury, multiligament injury or knee dislocation, incompatible to follow-up, and revision surgery. The study protocol was approved by the Selçuk University Faculty of Medicine Ethics Committee (approval number: 2019/53). A written informed consent was obtained from each patient. The study was conducted in accordance with the principles of the Declaration of Helsinki.

The treatment judgment criteria were knee laxity, Tegner Lysholm knee scores, ${ }^{[13]}$ the International Knee Documentation Committee (IKDC) scores, $^{[14]}$ knee mobility, Lachman test, and bone union.

The arthroscopic procedure was performed under spinal or general anesthesia. The patients were placed in the supine position as similar to the ACL reconstruction procedure. The surgery table was broken to allow full knee flexion (the opposite leg was held with a gynecologic leg holder) and a pneumatic tourniquet was inflated. Standard anteromedial and anterolateral parapatellar portals were generally sufficient for the entire procedure and rarely a third transpatellar portal (Gillquist)
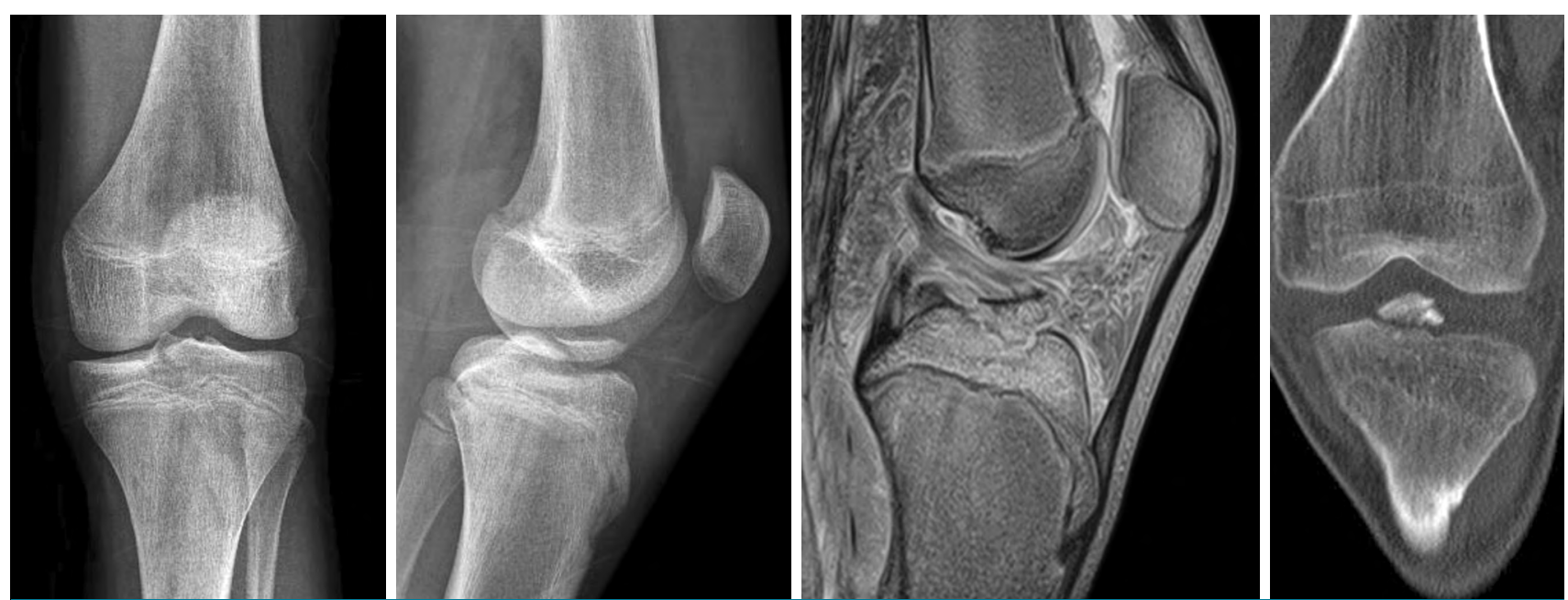

FIGURE 1. Standard diagnosis of tibial eminence fracture could be established with anteroposterior and lateral X-rays. If needed, magnetic resonance imaging and computed tomography examination should be performed. Figure presents operation images of a patient: anteroposterior and lateral X-rays as well as sagittal magnetic resonance imaging and coronal computed tomography section. 


\begin{tabular}{|c|c|c|c|c|c|}
\hline \multicolumn{6}{|c|}{ TABLE I } \\
\hline Patients & Sex & $\begin{array}{c}\text { Age } \\
\text { (year) }\end{array}$ & Cause of Injury & Follow-up months & $\begin{array}{l}\text { Return to daily } \\
\text { routines (months) }\end{array}$ \\
\hline 1 & Male & 16 & Road traffic accident & 16 & 3 \\
\hline 2 & Male & 17 & Sports injury & 18 & 5 \\
\hline 3 & Male & 23 & Road traffic accident & 17 & 2 \\
\hline 4 & Male & 34 & Fall & 15 & 4 \\
\hline 5 & Female & 15 & Fall & 11 & 7 \\
\hline 6 & Male & 16 & Road traffic accident & 14 & 2 \\
\hline 7 & Female & 22 & Road traffic accident & 13 & 4 \\
\hline 8 & Male & 14 & Road traffic accident & 21 & 3 \\
\hline 9 & Male & 18 & Sports injury & 19 & 5 \\
\hline 10 & Male & 17 & Road traffic accident & 8 & 4 \\
\hline 11 & Male & 21 & Sports injury & 24 & 8 \\
\hline 12 & Female & 27 & Skiing & 32 & 5 \\
\hline 13 & Male & 19 & Fall & 27 & 3 \\
\hline
\end{tabular}

was used when needed. A $4.5 \mathrm{~mm}$ diameter and 30-degree scope was used. First, a diagnostic arthroscopy was performed to understand the fracture pattern and its nature. Then, a $4 \mathrm{~mm}$ shaver was used to debride all the soft tissues, hematomas, and synovial materials around the fracture part. The anterior patellar fat pad was removed partially. Then, the fracture was reduced by the help of ACL C-ring tibial guide with an angle of 55 degrees through the medial portal and sometimes a probe was used to help reduction through the transpatellar portal. A small incision was performed on the anteromedial aspect of the proximal tibia allowing to contact the C-ring guide. A pin guide was used through the $\mathrm{C}$-ring guide from tibial cortex to reduce eminence. It should be kept in mind that the anterior placement of the pin guide may cause reduction loss and fracture segmentation during the surgical procedure. A $4.5 \mathrm{~mm}$ diameter drill was inserted through the pin guide. A metal lasso was sent to carry the double-loop endobutton device through the drill. Double-loop endobutton ropes were tightened and finally reduction was confirmed by the help of fluoroscopy (Figure 2).

The same rehabilitation program was planned for all patients: 30 to 60 degrees of knee flexion was permitted at early postoperative period and full flexion was allowed at the second week with the help of a brace. This brace was used for the first month and bearing weight was permitted as tolerated. Patients were evaluated at the outpatient clinic at first, third, and sixth months postoperatively to evaluate the rehabilitation and healing process (Figure 3).

\section{Statistical analysis}

All data were recorded into the IBM SPSS version 25.0 statistical software package (IBM Corp., Armonk, NY, USA). Descriptive statistical methods of frequency (n), percentage (\%), mean \pm standard deviation, and minimum-maximum were used in the evaluation of the data obtained from the study. P value of $<0.05$ was regarded as statistically significant.

\section{RESULTS}

Patients' mean follow-up time was $18.07 \pm 6.62$ months (range, 8 to 32 months) with a median of 17 months. IKDC scores were changed to percentiles and presented in Table II with Tegner Lysholm scores at first- and sixth-month outpatient clinic visits postoperatively. At first-month visit, mean IKDC scores were 38.0 \pm 7.0 and mean Tegner Lysholm scores were 50.3 \pm 5.8 . At sixth-month visit, mean IKDC scores were $80.2 \pm 4.0$

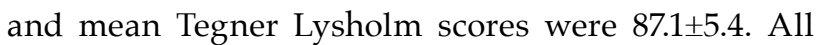
patients showed negative Lachman test and negative pivot-shift test at final follow-up. Radiological bone union without reduction loss was also seen in all patients (Figure 4). Four patients had difficulties regaining motion postoperatively because of a lack of rehabilitation. Two had hemarthrosis at early stage of postoperative period and arthropunction was performed so the ongoing rehabilitation process has been interrupted due to the arthropunction performed. 

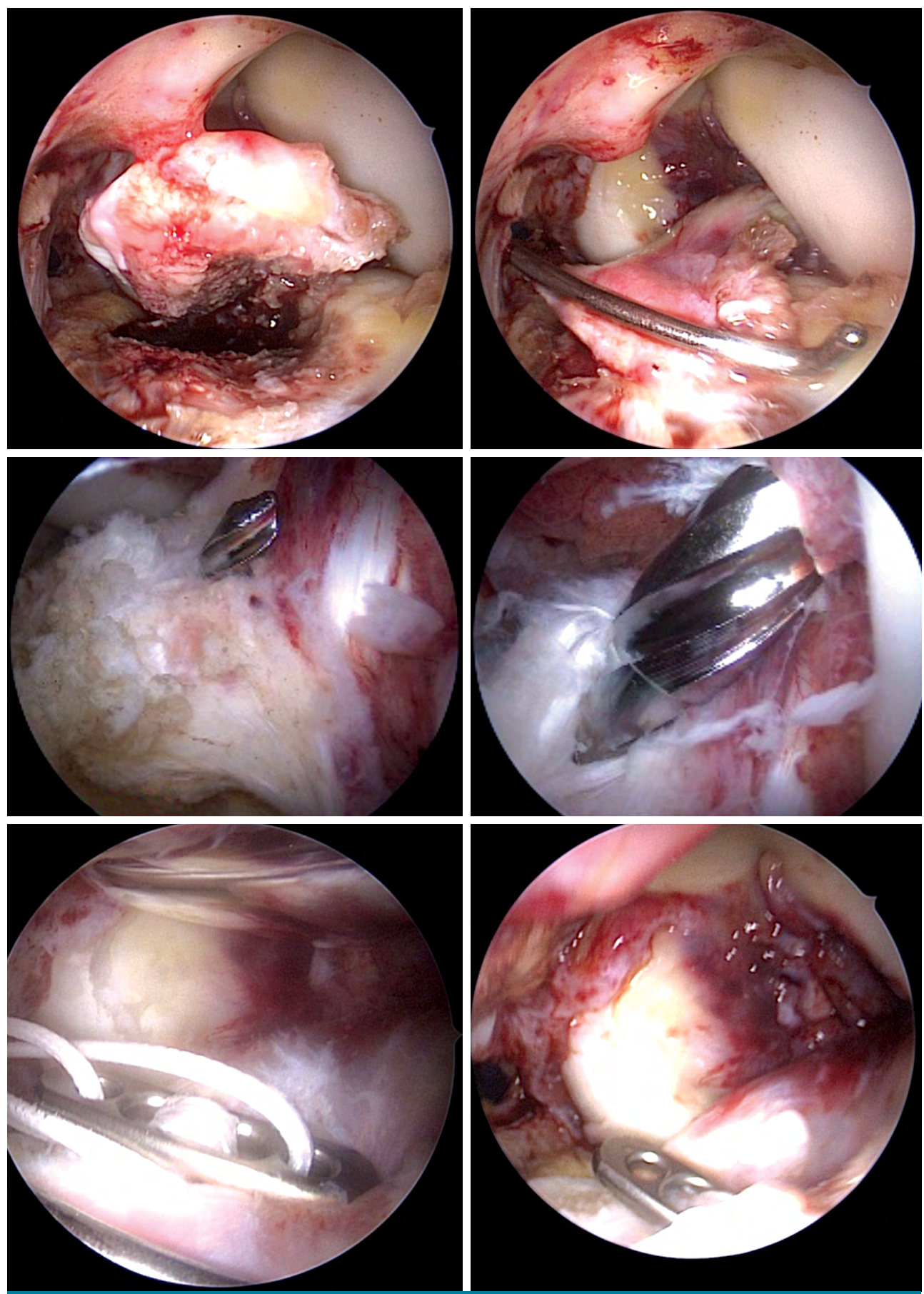

FIGURE 2. Steps of surgical procedure including identification of fracture, reduction of fragments, insertion of guide and drill, and last step fixation with double-loop endobutton.

At last visit, only minimal extension and flexion loss (up to 10 degrees) were seen in these patients (Table II). No deep infection or venous thrombosis was observed. None of the patients needed second operation for material removal because of implant disturbance. No arthrofibrosis was detected.

\section{DISCUSSION}

As the young and athletic population increases, the number of sports injuries, falls, and road traffic accidents also increase accordingly. Thus the importance of ACL injuries and eminence fractures also increases compared to previous years. ${ }^{[4]}$ With 

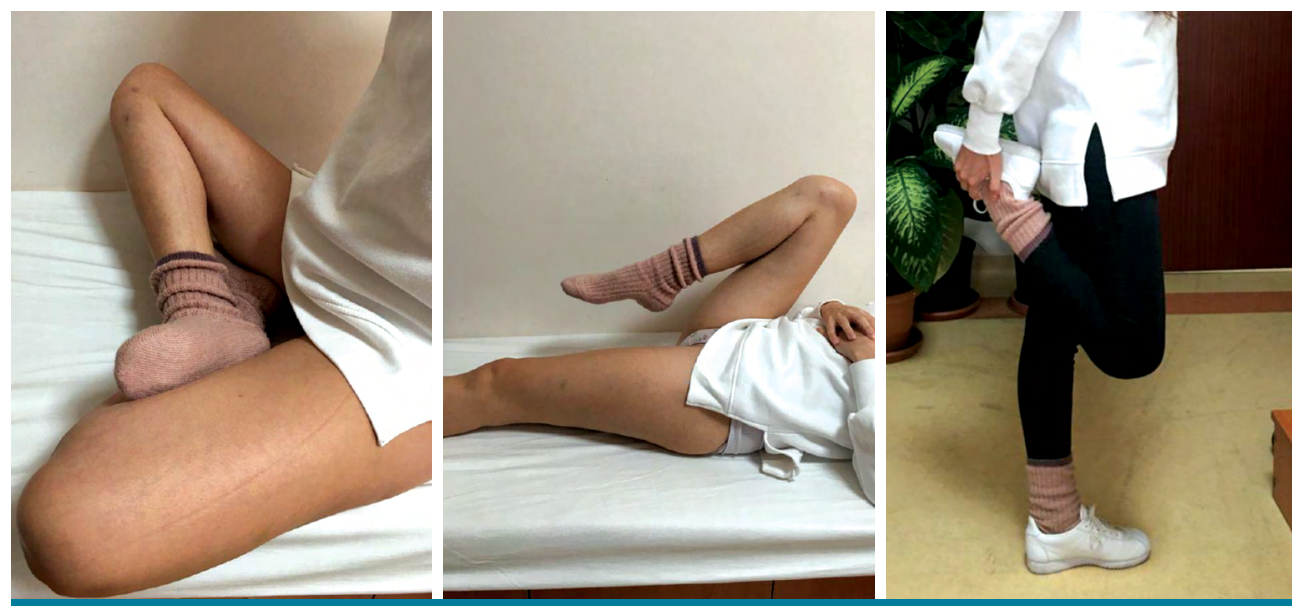

FIGURE 3. Outpatient clinic visit of a patient at postoperative sixth month with full range of motion and scars of arthroscopic portals and guide insertion.

the improvements in radiology, diagnoses of these injuries are established more easily while need for better treatment options arises.

The accepted consensus ${ }^{[3,5,15,16]}$ for the treatment of type II and type IIIa-b tibial eminence fractures is anatomic reduction and fixation of that articular defect. There are two options for the surgery of this region: open surgery or arthroscopic fixation. Arthrotomy techniques have many handicaps and more complications such as greater soft tissue damage, greater postoperative pain, longer hospital stay, and delayed rehabilitation. ${ }^{[15]}$ Arthroscopic approach has been successfully developed for diagnosis and treatment, reducing fracture fragments, treating concomitant soft tissue injuries, and recently fixing intraarticular fractures. Therefore, arthroscopic techniques are considered the gold standard for treatment of tibial eminence fractures. ${ }^{[5,6,16]}$

In arthroscopic surgery, the main aim is minimizing the rates of non-union, loss of range of motion, arthrofibrosis, and laxity allowing less soft tissue damage, shorter hospital stay and lower complication rates; however, little evidence is available to establish a decision in the best arthroscopic fixation method to

\begin{tabular}{|c|c|c|c|c|c|c|c|}
\hline & & & Fractı & types and $c$ & $\begin{array}{l}\text { Il } \\
\text { al scores of patie }\end{array}$ & & \\
\hline Patients & Sex & Grade & $\begin{array}{c}\text { IKDC } \\
1^{\text {st-month }}\end{array}$ & $\begin{array}{c}\text { IKDC } \\
6^{\text {th }} \text {-month }\end{array}$ & $\begin{array}{c}\text { Tegner Lysholm } \\
1^{\text {st }} \text {-month }\end{array}$ & $\begin{array}{c}\text { Tegner Lysholm } \\
6^{\text {th }} \text {-month }\end{array}$ & $\begin{array}{c}\text { Flexion and } \\
\text { extension deficits }\end{array}$ \\
\hline 1 & Male & $3 a$ & 44.80 & 79.30 & 53.00 & 89.00 & $0 / 0$ \\
\hline 2 & Male & 2 & 48.20 & 82.70 & 58.00 & 84.00 & $10 / 5$ \\
\hline 3 & Male & $3 b$ & 41.30 & 77.00 & 51.00 & 84.00 & $0 / 0$ \\
\hline 4 & Male & 2 & 47.10 & 78.10 & 55.00 & 84.00 & $5 / 5$ \\
\hline 5 & Female & $3 a$ & 31.00 & 73.50 & 55.00 & 79.00 & $5 / 10$ \\
\hline 6 & Male & 2 & 33.30 & 80.40 & 48.00 & 96.00 & $0 / 0$ \\
\hline 7 & Female & $3 a$ & 35.60 & 81.60 & 43.00 & 84.00 & $0 / 5$ \\
\hline 8 & Male & 2 & 37.90 & 83.90 & 52.00 & 95.00 & $0 / 0$ \\
\hline 9 & Male & $3 b$ & 39.00 & 80.40 & 38.00 & 86.00 & $10 / 5$ \\
\hline 10 & Male & $3 a$ & 31.00 & 81.60 & 51.00 & 91.00 & $0 / 0$ \\
\hline 11 & Male & 2 & 28.70 & 73.50 & 43.00 & 79.00 & $10 / 10$ \\
\hline 12 & Female & $3 b$ & 29.80 & 86.20 & 52.00 & 90.00 & $0 / 0$ \\
\hline 13 & Male & $3 a$ & 45.90 & 85.00 & 55.00 & 91.00 & $0 / 0$ \\
\hline
\end{tabular}



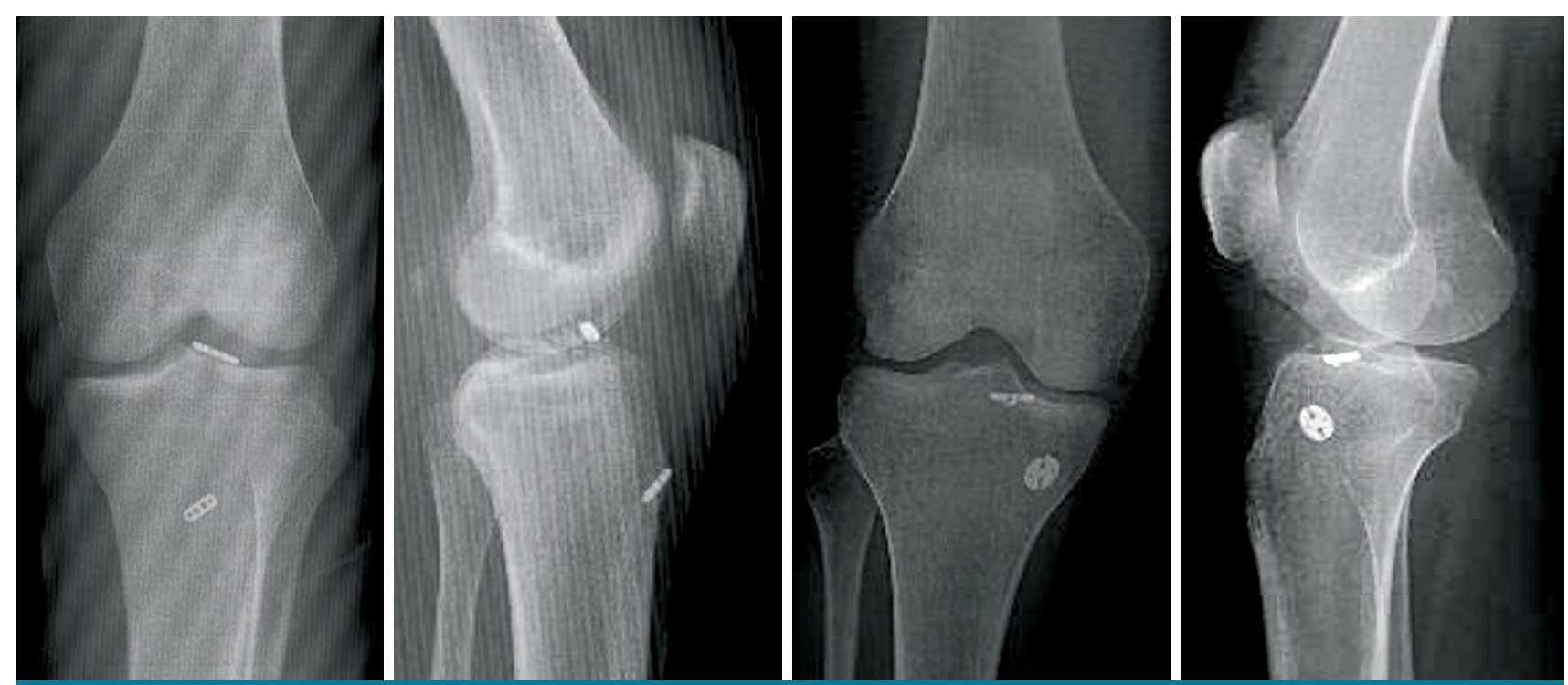

FIGURE 4. Postoperative anteroposterior and lateral X-rays of two different patients at postoperative sixth month. Fracture union can be seen at both $\mathrm{X}$-rays.

treat tibial eminence fractures. ${ }^{[6]}$ Arthroscopic fracture fixation can be achieved with Kirschner wires, staples, cannulated screws, absorbable nails, metallic screws, non-absorbable sutures or metallic wire. ${ }^{[5]}$ There is no gold standard for the arthroscopic fixation method, while there are some studies about the complications of cannulated screws, suture usage, and Kirschner wires as implant failure, future osteoarthritis and mal- and non-union. ${ }^{[5,6,6,15,16]}$ A fixation method with ease of applicability for arthroscopic approach with great stability, biocompatibility, and biomechanically strong fixation would be perfect for arthroscopic tibial eminence fixation. Previous studies about endobutton fixation strength were familiar for acromioclavicular joint ${ }^{[9,11]}$ and syndesmosis ${ }^{[10]}$ while there is no sufficient knowledge on tibial eminence fixation. Pape and Giffin $^{[17]}$ thought an alternative technique for arthroscopic treatment of tibial eminence fractures and published a case report of a patient treated using screw fixation with classic endobutton with continuous loop of polyester tape. This was the beginning of the endobutton fixation idea for tibial eminence fractures. Hapa et al. ${ }^{[18]}$ studied endobutton idea biomechanically at in vitro conditions in cadaver knee and revealed the idea of the usefulness of endobutton for tibial eminence fractures.

Faivre et al. ${ }^{[3]}$ performed the first and unique clinical study assessing the endobutton fixation in this indication and showed that it should certainly be supported by a larger series. The number of patients was eight in this study which showed that endobutton device was a simple technique allowing rigid fixation and early rehabilitation. Faivre et al. ${ }^{[3]}$ also reported five complications in their case series including arthrofibrosis and range of motion problems. Our study, including 13 patients, is one of the largest series for this surgical technique. The number of complications was only four. All four patients had motion problems, while two also had hemarthrosis during the early postoperative period. All range of motion problems were solved by physical therapy during the postoperative rehabilitation period in two months. According to us, this study is important with promising clinical and radiological results including all details of surgical images. Also, the sufficient follow-up duration and the systematical clinical and radiological examination data are the factors that add extra information to the literature for this surgical technique.

Zhang et al. ${ }^{[19]}$ tested a similar idea using a metal suture anchor fixed with a classic endobutton. However, this study had some handicaps as higher cost, more implants at knee joint, and open surgery for placing suture anchor. We used a biomechanically strong, double-loop endobutton implant to withstand the forces in the knee joint and the procedure was performed full arthroscopically just through holes.

Our study had some limitations such as the small patient group, limited follow-up duration, and lack of a control group. Although this study consisted of 13 patients, which can be evaluated as high compared with the literature, we believe that similar designed studies with larger sample sizes are required. 
Secondly, the mean follow-up duration of this study was 18.07 months, which is sufficient for shortterm results. Still, long-term follow-up results are needed for better understanding the advantages and disadvantages of this technique. The last limitation is the lack of a control group. This limitation was due to having no gold standard technique for tibial eminence fractures in the literature. Biomechanical studies are warranted to confirm this method and the obtained results should be reviewed.

In conclusion, these types of tibia fractures are seen very rarely and the literature for the arthroscopic treatment of eminence fractures with double-loop endobutton device is extremely restricted. We believe that this article is a good sample of the detailed technique presentation on 13 patients with excellent union to encourage other surgeons to use this technique. Our short-term results showed that using double-loop endobutton device was satisfactory to fix tibial eminence fractures. Further studies including higher numbers of patients with longer follow-up durations are needed for adequate results regarding this double-loop endobutton technique.

\section{Declaration of conflicting interests}

The authors declared no conflicts of interest with respect to the authorship and/or publication of this article.

\section{Funding}

The authors received no financial support for the research and/or authorship of this article.

\section{REFERENCES}

1. Meyers MH, McKeever FM. Fracture of the intercondylar eminence of the tibia. J Bone Joint Surg [Am] 1959;41-A:20920.

2. Atik OŞ. Surgical versus conservative treatment for torn anterior cruciate ligament. Jt Dis Relat Surg 2020;31:159-60.

3. Faivre B, Benea H, Klouche S, Lespagnol F, Bauer T, Hardy P. An original arthroscopic fixation of adult's tibial eminence fractures using the Tightrope ${ }^{\circledR}$ device: a report of 8 cases and review of literature. Knee 2014;21:833-9.

4. Zaricznyj B. Avulsion fracture of the tibial eminence: treatment by open reduction and pinning. J Bone Joint Surg [Am] 1977;59:1111-4.

5. Osti L, Buda M, Soldati F, Del Buono A, Osti R, Maffulli N. Arthroscopic treatment of tibial eminence fracture: a systematic review of different fixation methods. Br Med Bull 2016;118:73-90.
6. Gans I, Baldwin KD, Ganley TJ. Treatment and Management Outcomes of Tibial Eminence Fractures in Pediatric Patients: A Systematic Review. Am J Sports Med 2014;42:1743-50.

7. Thompson SM, Salmon LJ, Waller A, Linklater J, Roe JP, Pinczewski LA. Twenty-Year Outcome of a Longitudinal Prospective Evaluation of Isolated Endoscopic Anterior Cruciate Ligament Reconstruction With Patellar Tendon or Hamstring Autograft. Am J Sports Med 2016;44:3083-94.

8. Dung TT, Du HG, Long NH, Son LM, Thanh DX, Son DN, et al. Arthroscopic fixation of ACL avulsion fracture in the saint pault hospital: A review of treatment outcomes: Cohort study. Ann Med Surg (Lond) 2019;48:91-4.

9. Grantham C, Heckmann N, Wang L, Tibone JE, Struhl S, Lee TQ. A biomechanical assessment of a novel double endobutton technique versus a coracoid cerclage sling for acromioclavicular and coracoclavicular injuries. Knee Surg Sports Traumatol Arthrosc 2016;24:1918-24.

10. Schepers T. Acute distal tibiofibular syndesmosis injury: a systematic review of suture-button versus syndesmotic screw repair. Int Orthop 2012;36:1199-206.

11. Struhl S, Wolfson TS, Kummer F. Axial-Plane Biomechanical Evaluation of 2 Suspensory Cortical Button Fixation Constructs for Acromioclavicular Joint Reconstruction. Orthop J Sports Med 2016;4:2325967116674668.

12. Atik OŞ. Is there something new and interesting in my article? Eklem Hastalik Cerrahisi 2019;30:69.

13. Briggs KK, Kocher MS, Rodkey WG, Steadman JR. Reliability, validity, and responsiveness of the Lysholm knee score and Tegner activity scale for patients with meniscal injury of the knee. J Bone Joint Surg [Am] 2006;88:698-705.

14. Higgins LD, Taylor MK, Park D, Ghodadra N, Marchant M, Pietrobon R, et al. Reliability and validity of the International Knee Documentation Committee (IKDC) Subjective Knee Form. Joint Bone Spine 2007;74:594-9.

15. Bogunovic L, Tarabichi M, Harris D, Wright R. Treatment of tibial eminence fractures: a systematic review. J Knee Surg 2015;28:255-62.

16. Loriaut P, Moreau PE, Loriaut P, Boyer P. Arthroscopic treatment of displaced tibial eminence fractures using a suspensory fixation. Indian J Orthop 2017;51:187-91.

17. Pape D, Giffin R. Arthroscopic endobutton fixation for tibial eminence fractures: surgical technique. J Knee Surg 2005;18:203-5.

18. Hapa O, Barber FA, Süner G, Özden R, Davul S, Bozdağ E, et al. Biomechanical comparison of tibial eminence fracture fixation with high-strength suture, EndoButton, and suture anchor. Arthroscopy 2012;28:681-7.

19. Zhang Q, Yang J, Zhao G, Zheng D, Zhou X, Xu N, et al. A new technique for arthroscopic reduction and fixation of displaced tibial intercondylar eminence fractures, using suture anchor and EndoButton system. J Orthop Surg (Hong Kong) 2017;25:2309499016685011. 